Mathematical Sciences and Applications

E-NOTES

\title{
An Application of Path Analysis in Gaugeing Stimulated Travel Demand
}

\author{
Enver Cenan İnce*, İbrahim Demir and Hüseyin Murat Çelik
}

\begin{abstract}
This article aims to designate a methodological baseline for gaugeing stimulated travel demand in urban areas in the case of İstanbul in addition to the intention of detecting the primary factors affecting motorized trips in urban spaces so as to re-formulate current travel demand management policies. In this sense, this article exhibits an investigation on gaugeing stimulated travel demand in the case of İstanbul by interrogating the inter-relationship between two variables called amount of trips and travel time. Such an empirical investigation is expected to construct a baseline for determining the optimum transportation project with regard to the concern of minimizing the amount of travel time spent by communities. At this juncture, an amount of applied econometric models for measuring stimulated travel demand were exhibited in detail. According to the results of path analysis as an advanced version of simultaneous equations system, approximately $27 \%$ decrease in travel time causes $71 \%$ additional increase in amount of trips in a day. That is to say, a ten minutes decrese in travel time will trigger 108,869 more motorized trips per day in İstanbul. This result once more reveals that unending supply of transportation infrastructure in urban areas causes a kind of vicious circle in the long run, which necessitates further travel demand management strategies in all over the world.
\end{abstract}

Keywords: Applied econometric models; travel demand models; simultaneous equations model system, path analysis.

AMS Subject Classification (2020): Primary: 00A00 ; Secondary: 00B00; 00C00; 00D00; 00E00; 00F00.

${ }^{*}$ Corresponding author

\section{Introduction}

This article aims to open a door for gaugeing stimulated travel demand in a new way by investigating the mathemetical relationship between daily amount of trips and travel time per individual. From this point forth, the marginal effect of time allocated for daily trips on amount of trips per individual has been calculated with the help of a new methodological way called path analysis as an advanced version of simultaneous equations system, which is an extended version of classical simultaneous equations model, was designated. In this way, the estimations derived from this model can be benefitted in the selection the optimum large scale transportation project among of a bundle of alternatives in an urban scale. Also, it was taken into consideration that the time allocated for trips is a 
kind of friction parameter referring to a proxy measure of travel cost.

There are three main aims of this paper. Firstly, it is aimed to constitute a methodological baseline for gaugeing stimulated travel demand in urban areas in the case of İstanbul. Secondly, it is aimed to constitute a baseline for detection of primary parameters affecting motorized flow in urban spaces so as to re-formulate current travel demand management policies. Thirdly, the findings of this article can make classical travel demand forecasting models more dynamic and realistic.

In the light of this motivation, this article has been structured by five sections. In pursuit of introduction part, the basic theoretical background of gaugeing stimulated travel demand was reviewed. Then the data, materials and method were discussed in detail. The fourth section exhibited the preliminary results of the designated model, while the last section concludes all these efforts with some recommendations for future studies.

\section{Theoretical Background}

It is asserted that generated traffic decreases the benefits of new transportation investments, which also reincreases the cost of travel in the long run within the considerations of stimulated travel demand [1]. Herein, the cost can be represented by the travel time as a proxy variable in urban systems. Therefore, measuring stimulated travel demand in urban spaces seems a vital requirement so as to perceive the long run effects of any new large scale transportation investments in urban areas.

In this sense, within the considerations of gaugeing stimulated travel demand in literature, the variables included in the analyses were generally vehicle miles travelled as the dependent variable with the explanatory ones called travel time, travel speed, additional lane miles, time lagged geographical variables with follows to the socioconomical parameters [2,3]. Besides, the model structures in their analyses are called matched pair analysis, growth comparison analysis [2,4], two/three stages least squares regression models, auto-regressive models, and travel demand models [3,5]. Also, it is seen that in most of these models, the dependent variable, which is generally vehicle miles travelled, is modelled in the log-linear functional forms [3, 5].

On the other hand, there are some inefficiencies in these approaches. The first is about the study areas in that some of these studies focused on the corridor based analyses with grasping the marginal elasicity of vehicle miles travelled $[2,4]$, which refers to a kind of short run partial urban equilibrium disregarding the dynamics of whole urban areas. That is to say, urban area itself ought to be defined as the case area as a whole so as to grasp the long run urban equilibriums in such these considerations $[3,5]$. The second is about the aggregation of the data structures in that some researches aggregated the travel survey data by summing all observations on the urban communities scale $[2,6]$, which makes estimations errors increase dramatically $[5,6]$. The third is about disregarding the potential erogeneity of explanatory variables such as lane miles additions, travel time, etc. in their models [2, 5? -15], which is ought to be taken into consideration in such these related analyses [16-18].

From this point forth, in the studies gaugeing stimulated travel demand can be categorized into three approaches $[2,3]$. First is about the data structure in that whether the data is collected in an aggregated scale or in a behavioral units scale. In other words, whether the travel survey structure is designated by urban communities scale or individuals/household scale matters. Second is about whether the study area is defined as a whole urban area or just as a corridor/ highway based line in related analyses. Third is about the model structures in related analyses in that whether the erogeneity of any explanatory variable affecting stimulated travel demand is taken into consideration or not $[2,3]$.

In the light of these views, our paper investigates the marginal interaction between amount of trips (instead of vehicle miles travelled) and travel time, since amount of trips is much more direct measure of stimulated demand rather than the vehicle miles travelled in urban spaces with taking the followings into consideration:

i. Taking the endogeneity of travel time into account [16-18].

ii. Instead of the aggregated data structures, the travel surveys are needed to be produced by the behavioral units scale with regard to individuals $[5,6]$ instead of aggregation towards urban communities.

iii. Study area ought to be defined as the whole urban area $[3,5]$ instead of the corridor based ones $[2,4]$. 


\section{Data, Materials and Method}

According to the research design of this article, the term traveller should firstly be defined. In this study, traveller is defined as the one, who is above 16 years old. Secondly, the term trip is defined as the motorized mobility, which does not return to its origin within 15 minutes. From this viewpoints, the sample was selected by the procedure of stratified simple random sampling in İstanbul metropolitan region and the survey was coordinated by Transportation Department of the Metropolitan Municipality. The sample referred to 90,000 households with the sampling ratio $3 \%$ and two-stages random cluster sampling procedure was implemented. In the first stage, 4,000 primary household units were randomly selected, while 30 household units per 90 were systematically selected in the second stage. Thus, 450 traffic zones were constructed as the spatial analyzing units with refers to 356,000 trips with the records of origins and destinations.

From this point forth, the variables in the analyses were defined as in the followings:

- number_trip: amount of trips exhibited per individual per day.

- travel_time: amount of minutes spent on travel per day.

- travel_distance: length of $\mathrm{km}$ travelled per day.

- sex: dummy variable; 1 : male, 0: female.

- household_head: dummy variable; 1: household head, 0: others in the family.

- household_income: monthly household income in Turkish Lira per month.

- vehicle_number: number of automobiles owned.

- household_size: number of individuals in the family.

- age: age of the person.

- home_base_work: dummy variable; 1: if the recorded trip is from home to work, 0: otherwise.

- home_base_school: dummy variable; 1 : if the recorded trip is from home to school, 0: otherwise.

- education_year: amount of years spent in education by the individual.

- free_flow_time: the hypothetical travel time in minutes experienced in the free flow speed as the only vehicle in the highway system.

- motorized_flow: dummy variable; 1 : if at least one motorized trip is exhibited by the individual, 0: otherwise.

In the light of these variables, to begin with, number of trips behaves as a discrete count variable and it involves excess amount of zero observations in that almost $63 \%$ of them is zero (see Figure 1). Secondly, unlike amount of trips, travel time is a kind of gaussian distributed variable.

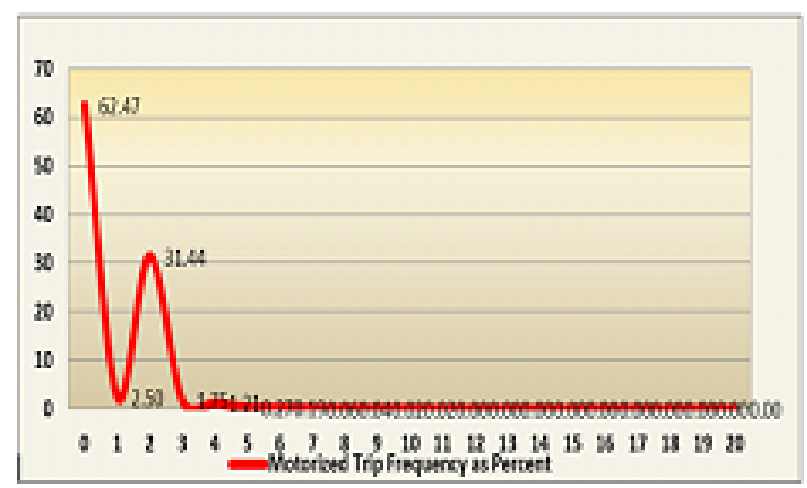

Figure 1. Daily trip frequencies produced by STATA 15. 
Thirdly, amount of minutes spent in travel is a kind of endogenous variable in explaining amount of trips, which necessitates simultaneous system. But, classical simultaneous equations system assumes that both dependent and the endogenous explanatory variable(s) are gaussian distributed continuous variables, which is not the case in this study since amount of trips is a count variable.

In the light of these views, non linear regression models come into agenda in modelling the count variable called amount of daily trips. These models are poisson regression and negative binomial regression [19, 20].

In the structure of poisson regression, the dependent variable for $i^{\text {th }}$ observation called $y_{i}$ is assumed to be poisson distributed with mean $\lambda_{i}$, then Equation 3.1 is:

$$
\begin{gathered}
f\left(Y_{i}=y_{i}\right)=\frac{e^{-\lambda_{i}} \times \lambda_{i}^{y_{i}}}{y_{i} !} ; y_{i}=0,1,2, \ldots \\
f: \text { probability distrubution function }
\end{gathered}
$$

Then, the mathematical equation between $\lambda_{i}$ and $x_{i}$ is as in Equation 3.2:

$$
\ln \left(\lambda_{i}\right)=\beta^{\prime} \times x_{i}
$$

In addition, poisson regression structure necessitates the condition that conditional mean of the dependent variable (given the explanatory variables $x_{i}$ 's) is equal to conditional variance of this variable as represented in equation 3.3:

$$
E\left[y_{i} \mid x_{i}\right]=\operatorname{Var}\left(y_{i} \mid x_{i}\right)=\lambda_{i}=e^{\beta^{\prime} \times x_{i}}
$$

Then, the marginal elasticity of amount of trips $\left(y_{i}\right)$ with regard to the marginal change in travel time is explained by Equation 3.4:

$$
\frac{\partial E\left[y_{i} \mid x_{i}\right]}{\partial x_{i}}=\operatorname{Var}\left(y_{i} \mid x_{i}\right)=\lambda_{i} \times \beta=\lambda_{i} \times e^{\beta^{\prime} \times x_{i}}
$$

So, the maximum likelihood function in poisson regression system becomes as revealed in Eequation 3.5:

$$
\ln (L)=\sum_{i=1}^{n}\left(-\lambda_{i}+y_{i} \times \beta^{\prime} \times x_{i}-\ln \left(y_{i} !\right)\right)
$$

On the other hand, the assumption of poisson regression system, which asserts that conditional mean of the dependent variable is equal to conditional variance of this variable, is not usually realistic in most cases. In this sense, it is indicated that the condition of overdispersion is observed in most cases, which makes negative binomial regression system more attractive [21]. This system can be revealed as in the following Equation 3.6 with the help of $\theta$ as a scale variable:

$$
f\left(y_{i} \mid x_{i}\right)=\frac{r\left(\theta+y_{i}\right)}{r(\theta) \times r\left(y_{i}+1\right)} \times r_{i}^{y} \times\left(1-r_{i}\right)^{\theta}
$$

where $r_{i}=\frac{\lambda_{i}}{\lambda_{i}+\theta_{i}}$. So the related mean still stays as $\lambda_{i}$ as in the poisson system, while the variance takes its new form as $\lambda_{i} \times\left(1+\frac{1}{\theta}\right) \times \lambda_{i}$ due to the case of overdispersion. Then, the related marginal elasticity can still be derived as revealed in Equation 3.4 [19].

In addition, the most commonly used test in the selection between the poisson and negative binomial regression systems is likelihood ratio (LR) test [19, 22], which is represented as in Equation 3.7: 


$$
L R=2 \times\left[\ln \left(L_{N B M}\right)-\ln \left(L_{P M}\right)\right]
$$

Herein, if the calculated value of LR is larger than the critical value in the asserted confidence interval, then this signs that there is the case of overdispersion that favours negative binomial system.

As it is explained in the following section of the article, although the negative binomial system is preferred as the single equation model in modelling number of trips, it can not deal with the excess zero observations in this variable. This situation makes zero truncated models come into account, since it can cope with excessive amount of zero counts in the dependent variable. [20].The mathematical function behind this model structure is as revealed in Equation 3.8:

$$
F(y \mid \theta, y \geq 1)=\frac{f(y \mid \theta)}{1-F(0 \mid \theta)}, y=1,2, \cdots
$$

Here $f(y \mid \theta)$, probability distribution function, $F(y \mid \theta)=\operatorname{Prob}[Y \leq y]$, cumulative probability distribution function of $y$, and $\theta$ is a vector of parameters.

On the other hand, all these asserted regression systems refer to single equations system, which disregards the erogeneity of an independent variable in the system [19, 20,22-24], which is minutes spent in daily travel in our case. Therefore, simultaneous equations system, which can cope with the problem of such this erogeneity, comes into considerations. Unlike single equation models, endogenous explanatory variable can be taken as the other dependent variable that is also affected by the priority defined dependent variable in such this equations system. This can be succeeded by asserting convenient instrumental variable(s) in the system [19, 20]. On the other hand, the failure of this system in our case is due to the assumption of classical simultaneous equations system asserting that both dependent and endogenous variables are continuous ones, since trip counts is not Gaussian distributed. Therefore, an extended version of classical simultaneous equations system, which is called path analysis as an advanced version of simultaneous equations system, comes into considerations for our case.

In the designation of this model structure, firstly, trip counts per person is estimated by negative binomial regression system. Then, these estimated values (e_number_trip) are used as further explanatory observations in modelling the endogenous variable called minutes spent in travel (see Figure 2).

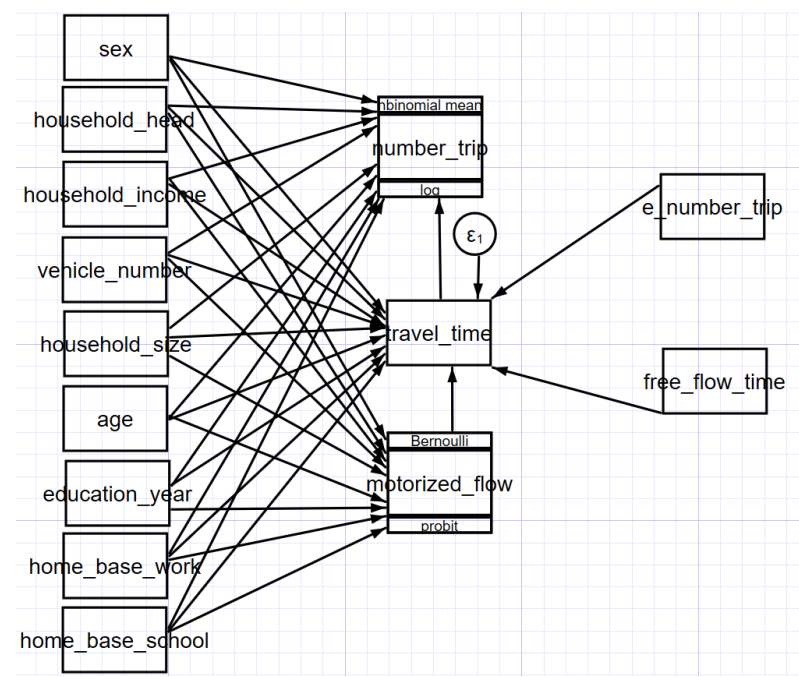

Figure 2. Designation of path analysis by STATA-15 SEM Builder.

Furthermore, in pursuit of finalization of the structure of the path analysis, the mathematical mechanism for grasping marginal elasticities between related variables involving especially the marginal effect of minutes spent in 
travel on number of trips come into considerations.

In this sense, to begin with, the marginal elasticity calculation with regard to the non-linear models can basically be represented by Equation 3.9:

$$
M E=\frac{\partial E[Y \mid X]}{\partial X_{j}}
$$

Here, ME represents marginal elasticity and $E($.$) stands as the expected value function. From this point forth,$ this equation gets its new form as in Equation 3.10 by indicating a function $g($.$) that represents the function of$ non-linear mean values:

$$
E[Y \mid X]=g\left(X^{\prime} \times \beta\right), \frac{\partial E[Y \mid X]}{\partial X_{j}}=g^{\prime}\left(X^{\prime} \times \beta\right) \times \beta_{j} .
$$

Then, the model structures involving multi explanatory variables requires the calculation of relative effects of changes in regressors, which can be represented by Equation 3.11:

$$
\frac{\partial E[Y \mid X] / \partial X_{j}}{\partial E[Y \mid X] / \partial X_{k}}=\frac{\beta_{j}}{\beta_{k}} \times \frac{g^{\prime}\left(X^{\prime} \times \beta\right)}{g^{\prime}\left(X^{\prime} \times \beta\right)}=\frac{\beta_{j}}{\beta_{k}} .
$$

On the other hand, within the concept of finite difference method, Equation 3.11 is modified by Equation 3.12:

$$
\frac{\Delta E[Y \mid X]}{\Delta X_{j}}=g\left(X+e_{j}, \beta\right)-g(X, \beta) .
$$

Here, $e_{j}$ represents the $j^{t h}$ element of the vector, in which the other elements are zero. Lastly, in the exponential distribution functions the equation above is transferred to Equation 3.13 below [20]:

$$
E[Y \mid X]=e^{X^{\prime} \times \beta}, \frac{\partial E[Y \mid X]}{\partial X_{j}}=E[Y \mid X] \times \beta_{j} .
$$

In the light of these mathematical derivations, the marginal elasticity estimation between number_trip and travel_time per each traveller $i$ in our case can be represented by Equation 3.14:

$$
\frac{1}{N} \times \sum_{i=1}^{N} \frac{\partial E\left[\text { number_trip }_{i} \mid X_{i}, \text { travel_time }_{i}\right]}{\partial\left(\text { travel_time }_{i}\right)}
$$

Also, the marginal elasticity of each explanatory variable $X_{i}$ on the number of trips per each individual $i$ can be indicated by Equation 3.15:

$$
\frac{\partial E\left[\text { number_trip } i X_{i}, \text { travel_time }_{i}\right]}{\partial\left(X_{i}\right)}
$$

To sum, the path analysis as an advanced and extended version of classical simultaneous equations system is the most convenient model concept in our case since it can cope with non-linearity of daily trip counts, excess zero amounts in trip counts, and erogeneity of travel time (see Table 1). 
Table 1. Results of Poisson and Negative Binomial Regression Systems.

\begin{tabular}{|c|c|c|c|c|c|c|c|}
\hline Poisson Regression & Coefficient & Standard Error & $\mathrm{z}$ & Negative Binomial & Coefficient & Standard Error & $\mathrm{z}$ \\
\hline $\operatorname{sex}$ & 0.0817799 & 0.0083001 & 9.85 & $\operatorname{sex}$ & 0.029871 & 0.0071096 & 4.2 \\
\hline household_head & 0.1405562 & 0.009524 & 14.76 & household_head & 0.1075885 & 0.0076744 & 14.02 \\
\hline household_income & $6.79 \mathrm{e}-06$ & $1.58 \mathrm{e}-06$ & 4.3 & household_income & $7.80 \mathrm{e}-06$ & $1.93 \mathrm{e}-06$ & 4.05 \\
\hline vehicle_number & 0.1617351 & 0.0053751 & 30.09 & vehicle_number & 0.1146227 & 0.0049238 & 23.28 \\
\hline household_size & -0.0137819 & 0.0020895 & -6.6 & household_size & -0.0138107 & 0.0017256 & -8 \\
\hline age & -0.0020655 & 0.0003179 & -6.5 & age & 0.0020207 & 0.0002602 & -7.77 \\
\hline education_year & 0.0311067 & 0.001005 & 30.95 & education_year & 0.0240298 & 0.0007979 & 30.12 \\
\hline travel_time & 0.0054185 & 0.0000725 & 73.77 & travel_time & 0.0085438 & 0.0000896 & 95.37 \\
\hline home_base_work & 0.9484354 & 0.0098287 & 96.5 & home_base_work & 0.7390091 & 0.0087332 & 84.62 \\
\hline home_base_school & 0.8404261 & 0.0147617 & 56.93 & home_base_school & 0.6927652 & 0.0117506 & 58.96 \\
\hline free_flow_time & 0.1482236 & 0.0206504 & 7.18 & free_flow_time & 1.516752 & 0.0416975 & 36.38 \\
\hline \multirow[t]{3}{*}{$\_$constant } & -1473.417 & 0.0201662 & -73.06 & constant & -1.712916 & 0.0163486 & -104.77 \\
\hline & & & & /lnalpha & -1.368784 & 0.0397883 & \\
\hline & & & & alpha & 0.2544163 & 0.0101228 & \\
\hline
\end{tabular}

\section{Results}

To begin with, as seen from the results of poisson and negative binomial regression systems (see Table 1), there exists the case of overdispersion, which makes negative binomial system more preferable (remember Equation 3.7). That is why in the path analysis design, the equation for number of trips is exhibited by negative binomial system.

\section{LRTest(Equation3.7)Result :}

$2 \times[\ln (173215.72)-\ln (182318.45)]=0.1024343$ and this value is larger than the critiqual chi square value for 2 degrees of freedom in $95 \%$ confidence level $(0.1024>0.10)$.

In addition, according to the results of path analysis (see Table 2), it is seen that all coefficient of related variables are statistically significant in at least $99 \%$ confidence level.

For the considerations of signs of the coefficients, the sign of the estimated coefficient of household size is negative in the model of motorized_flow that reveals the probability to produce at least one motorized flow decreases as the household size increases (see Table 2). This will be the effect of budget constraints in the Turkish families. Also, the sign of the age is positive in the same model of motorized flow, which shows that the probability of exhibiting motorized flow in a day explicitly increases as age increases. On the other hand, the sign of age is negative in the model of number_trips. This will be the case since the retired ageing population tend to exhibit more recreation trips as a replacement of the home based work ones in the case of Istanbul.

Furthermore, estimated coefficient of travel time is negative in the model of number_trip, which is already expected theoretically in that as the travel time decreases, amount of trips increases with regard to the considerations of stimulated travel demand.

In addition, according to the marginal elasticity estimations in pursuit of results of path analysis, a unit decrease in the minutes spent on travel causes an additional increase in the amount of trips by 0.000953 (see Table ??). That is to say, an approximately $27 \%$ decrease in travel time stimulates $70.4 \%$ additional motorized flow in the case of Istanbul.

Furthermore, the leading parameters enhancing the level of motorized flow are sex, household head, and vehicle_number. According to the estimations, per male intends to produce 0.1597 more trips than per female and the household head is 0.256 more inclined to produce a motorized flow than the other members in the family in a day. Also, additional vehicle purchased by the family causes an increase of 0.1884 more motorized flow in the family in Istanbul (see Table ??).

In addition, the marginal effect of household size and age on motorized flow are 0.028 and 0.0017 with negative signs (see Table ??). This reveals that as one more traveller, who is above 16 years old, is involved in the family, the amount of motorized flow decreases by 0,028 and if the individuals gets one year older, then the amount of daily trips decreases by 0.0017 .

Besides, income per month of each household seems as the least prominent parameter stimulating daily motorized flow with the marginal elasticity estimations 0.000025 , which means that an amount of 10,000 TL increase in income of the family per month brings about only 0.025 additional trip per day per person in the family. This result is interesting, since it is unlike for most of the cities of developed countries in that income seems as the leading parameter affecting daily mobility, which is not the case in Istanbul. 
Table 2. Results of Path Analysis.

\begin{tabular}{|c|c|c|c|}
\hline Variable & Coefficient & Standard Error & $\mathrm{z}$ \\
\hline & motorized_flow & & \\
\hline sex & 0.0876364 & 0.0088781 & 9.98 \\
\hline household_head & 0.1824174 & 0.0098624 & 18.50 \\
\hline household_income & 0.0000381 & $5.01 \mathrm{e}-06$ & 7.60 \\
\hline vehicle_number & 0.2149051 & 0.0060338 & 35.62 \\
\hline household_size & -0.0340989 & 0.0020449 & -16.68 \\
\hline age & 0.000905 & 0.0002754 & 3.29 \\
\hline education_year & 0.0537412 & 0.0010146 & 52.97 \\
\hline home_base_work & 1.448814 & 0.0078503 & 184.55 \\
\hline home_base_school & 1.230701 & 0.0139649 & 88.13 \\
\hline \multirow[t]{2}{*}{ _constant } & -1.498341 & 0.0181383 & -82.61 \\
\hline & number_trip & & \\
\hline sex & 0.094116 & 0.0078328 & 12.02 \\
\hline household_head & 0.1502352 & 0.0086166 & 17.44 \\
\hline household_income & 0.0000143 & $2.67 \mathrm{e}-06$ & 5.35 \\
\hline vehicle_number & 0.1087255 & 0.0053448 & 20.34 \\
\hline household_size & -0.0162595 & 0.0019109 & -8.51 \\
\hline age & -0.0010601 & 0.0002899 & -3.66 \\
\hline education_year & 0.0430605 & 0.0008928 & 48.23 \\
\hline home_base_work & 1.052222 & 0.0101024 & 104.16 \\
\hline home_base_school & 1.042079 & 0.0122483 & 85.08 \\
\hline free_flow_time & 2.269169 & 0.0490115 & 46.30 \\
\hline _constant & -1.65532 & 0.0177808 & -93.10 \\
\hline \multirow[t]{2}{*}{ travel_time } & -0.0023983 & 0.0000523 & -45.89 \\
\hline & free_flow_time & & \\
\hline travel_distance & 0.0102411 & 0.000213 & 48.07 \\
\hline motorized_flow & 0.2824551 & 0.0030349 & 93.07 \\
\hline \multirow{2}{*}{ _constant } & $-7.54 \mathrm{e}-18$ & $1.28 \mathrm{e}-19$ & -58.70 \\
\hline & travel_time & & \\
\hline g_number_trip & 7.415484 & 0.4303755 & 17.23 \\
\hline \multirow[t]{2}{*}{ _constant } & 30.81517 & 0.3910488 & 17.23 \\
\hline & /number_trip & & \\
\hline lnalpha & -0.8130799 & 0.030545 & \\
\hline $\operatorname{var}\left(e_{-} f r e e \_f l o w \_t i m e\right)$ & 0.0407052 & 0.0113116 & \\
\hline \multirow[t]{2}{*}{ var(e_travel_time) } & 3392.502 & 41.8371 & \\
\hline & Logpseudolikelihood $=-1314459.5$ & & \\
\hline
\end{tabular}

Lastly, the justification of the model specification called path analysis is summarized in the table below (Table 4).

Table 4. Model Comparions.

\begin{tabular}{|c|c|c|c|}
\hline Model & Competing with the non-linearity of daily amount of trips per head & Competing with excess amount of zero observations in the trip counts & Taking endogeneity into account \\
\hline $\begin{array}{l}\text { Poisson Regression Model (PRM) } \\
\text { PRM }\end{array}$ & Tick & & \\
\hline Negative Binomial Regression Model (NBRM) & Tick & $\mathrm{x}$ & $\mathrm{x}$ \\
\hline Zero Truncated Models & Tick & $\mathrm{x}$ & $\mathrm{x}$ \\
\hline Classical Simultaneous Equations Model (SEM) & & $\mathrm{x}$ & Tick \\
\hline Path Analysis & Tick & Tick & Tick \\
\hline
\end{tabular}

\section{Concluding Remarks}

The findings of this article has three multiplicative effects. First is about the way of gaugeing the stimulated travel demand in a new methodological proposal. In this sense, the variables and the designation of the path analysis can be extended and generalized in the cases of other cities of different countries in all over the World. Second multiplicative effect is about the detection of the prominent parameters affecting motorized mobility in an urban area. Herein, sex, household head and number of vehicles in the family come into prominence stimulating 
daily motorized flow in the case of Istanbul. This can be extended and verified in other cities of Turkey, and then the common leading parameters will be taken into considerations as the control parameters in the travel demand management formulations. To illustrate, the cities can be categorized by their scores called per cent of males, per cent of household head among population, and automobile ownership ratio per household, and then the provinces with the highest scores can be prioritized in the applications of travel demand management policies. Same procedure also Works for any province(s) of any country in the World.

The third multiplicative effect of this article is that the marginal elasticity estimation between amount of trips and travel time can be integrated into the classical travel demand models in that the first stage of motorized trip production shapes the last stage called network assignment with its related optimum total system travel time, and then the new finding of travel time re-affects the first stage of trip production. In this sense, the findings of this article can make classical four stages travel demand forecasting models much more dynamic and realistic.

\section{Acknowledgment.}

We thank the reviewer for their insightful comments and suggestions that helped us improve the paper.

\section{Funding}

There is no funding for this work.

\section{Availability of data and materials}

Not applicable.

\section{Competing interests}

The authors declare that they have no competing interests.

\section{Author's contributions}

All authors contributed equally to the writing of this paper. All authors read and approved the final manuscript.

\section{References}

[1] Litman, T. (2021). Generated Traffic and Induced Travel Implications for Transport Planning. Victoria Transport Policy Institute.

[2] Pells, S. (1989). User response to new road capacity: A review of published evidence. University of Leeds, Institute of Transport Studies, Workin Paper 283.

[3] Vos, J., \& Witlox, F. (2013). Transportation policy as spatial planning tool; reducing urban sprawl by increasing travel costs and clustering infrastructure and public transportation. Journal of Transport Geography, 33, 117-125.

[4] Mokhtarian, P., Samaniego, F., Shumway, R., Willits, N., \& Azari, R. (2000). Analyzing induced traffic from capacity enhancements used matched pairs: A California Study. Davis: University of California, Institute of Transport Studies .

[5] Hansen, M., \& Huang, Y. (1997). Road supply and traffic in California urban areas. Transportation Research Part A , 31, 205-218.

[6] Barr, L. (2000). Testing for the significance of induced highway travel demand in metropolitan areas. Transportation Research Record: Transportation Planning, Public Participation, and Telecommuting(1706), 1-8.

[7] Hansen, M., Gillen, D., Dobbins, A., Huang, Y., \& Puvathingal, M. (1993). The air quality impacts of urban highway capacity expansion: Traffic Generation and land use change. Berkley: University of California, Institute of Transportation Studies. 
[8] Kroes, E., Daily, A., Gunn, H., \& Van der Hoorn, T. (1996). The opening of the Amsterdam ring road: A case study of short term impacts on removing bottleneck. Transportation, 23, 71-82.

[9] Luk, J., \& Chung, E. (1997). Induced demand and road investment: An initial appraisal. ARR 299. Vermont South, Australia: ARRB Transportation Research

[10] Fulton, L., Meszler, D., Noland, R., \& Thomas, J. (2000). A statistical analysis of induced travel effects in the U.S. mid- Atlantic region. Journal of Transportation and Statistics, 3(1), 1-14.

[11] Silva, A., \& Costa, G. (2007, September). Urban sprawl and energy use for transportation in the largest Brazilian cities. Energy for Sustainable Development , 3(6), 44-50.

[12] Ozuysal, M., \& Tanyel, S. (2008). Induced travel demand in developing countries : Study on state highways in Turkey. Journal of Urban Planning and Development -ASCE, 134(2), 78-87.

[13] Holcombe, R., \& Williams, D. (2010). Urban Sprawl and Transportation Externalities. The Review of Regional Studies, 3(40), 257-273.

[14] Hymel, K., Small, K., \& Dender, K. (2010, February 5). Induced Demand and Rebound Effects in Road Transport

[15] Melo, P., Graham, D., \& Canavan, S. (2012). The Effects of Road Investments on Economic Output and Induced Travel Demand: Evidence for Urbanized Areas in the US. Transportation Research Board: Journal of the Transportation Research Board.

[16] Noland, R., \& Cowart, W. (2000). Analysis of metropolitan highway capacity and the growth in vehicle miles of travel. Transportation, 27(4), 363-390.

[17] Cervero, R., \& Hansen, M. (2002). Induced travel demand an induced road investment: A simultaneousequation analysis. Journal of Transport Economics and Policy, 36, 469-490.

[18] Cervero, R. (2003). Road expansion, urban growth, and induced travel: A path analysis. Journal of the American Planning Association, 69(2), 145-163.

[19] Green, W. (2007). Limdep version 9.0. Econometric modeling guide , v.2. New York: Plainview.

[20] Cameron, C., \& Trivedi, P. (2005). Microeconometrics:Methods and Applications. New York: Cambridge University Press.

[21] Kennedy, P. (1998). A guide to econometrics. Cambridge, Massachusetts: The MIT Press.

[22] Green, W. (2003). Econometric Analysis (5th ed.). New Jersey: Pearson.

[23] Long, J. (1997). Regression models for categorical and limited dependent variables. London, New Delhi: Thousand Oaks: Syaş Publications.

[24] Winkelmann, R. (2008). Econometric analysis of count data (Cilt 5). Verlag, Berlin, Heidelberg: S pringer.

\section{Affiliations}

ENVER CENAN İNCE

AdDress: Sivas Cumhuriyet University, Dept. of City and Regional Planning, Sivas, Turkey

E-MAIL: :eince@cumhuriyet.edu.tr

ORCID ID:0000-0002-8264-6707

IBRAHIM DEMIR

ADDRESS: Yildiz Technical University, Dept. of Statistics, Istanbul, Turkey.

E-MAIL: idemir@gmail.com

ORCID ID:0000-0002-2734-4116 
HÜSEYIN MURAT ÇELIK

ADDRESS: Istanbul Technical University, Dept. of City and Regional Planning, Istanbul, Turkey E-MAIL: celikhus@itu.edu.tr

ORCID ID:0000-0001-9647-868X 